\title{
Two Contexts for Training Teachers of Native Languages ${ }^{1}$
}

Kelleen Toohey and Pamela Hansen

This paper reports on our experience in Native language teacher training in two contexts in British Columbia: one a universitysponsored course offered in a northern community, and one a workshop-based inservice course offered in the Fraser Valley. Work done with the students is described, excerpts of student work are presented and suggestions about Native language teacher training in Canada are made.

In March 1982, TESL-Canada organized a symposium entitled "Language Development in Native Education." Some of the symposium participants were English-speaking teachers of Native ${ }^{2}$ students and others were teachers of Native languages; all were concerned generally with the linguistic development of Native students and with techniques, curricula and ideas which would improve the teaching of language to Native students. It became clear during the meetings that these teachers wished to continue working together to attempt to coordinate approaches to Native students' development of language competency, both in a national language and in the students' Native languages. These teachers of Native students advocated a bilingual approach to Native education. Participants discussed, among other issues, teacher preparation and made recommendations which concerned the training both of persons who work in English with Native students and also of persons who work in Native languages with students. This paper contributes to that discussion in that it attempts to document our experience in working with the training of Native language teachers in two contexts in British Columbia.

British Columbia has the greatest variety of distinct Native Indian languages of any province or territory in Canada. However, since European contact there has been a steady decline in the number of speakers of those Native languages. In British Columbia currently, especially in many Native communities close to urban centres, many children are not learning Native languages as first languages, and the only fluent Native language speakers are quite elderly. It is becoming clear to many Native people in British Columbia that their languages are very seriously threatened with extinction in the near future. Responses made to this threat of extinction have been various: some Indian bands have contracted with linguists to create orthographies for previously unwritten languages, 
and/or to develop dictionaries for those languages which did not have them. Bands have also worked to initiate or strengthen programs for teaching Native languages to school students and currently, there are persons working in British Columbia schools who teach Native languages. Training for those Native language teachers has become an important concern. ${ }^{3}$

Some Native language teachers in B.C. have had some systematicallyplanned training, but this is not generally the case. What is more typical is for the community-based Native language teacher to have acted as an informant or as a co-worker with a linguist in developing an orthography and/or a dictionary for a language, to have attended teacher training workshops planned by a variety of agencies, and to have had experience working with children in classrooms. Kirkness (1984) outlines what she calls the "impossible task" facing untrained teachers of Canadian Native languages: designing curriculum for kindergarten to grade twelve students, preparing lesson plans and manufacturing materials, and working with students in classrooms. Pauline Alfred, an experienced teacher of Kwak'wala at Alert Bay, British Columbia, voiced a common concern in a discussion with other Native language teachers in 1983:

I still say that it's really unfair when they just grab us and throw us into a classroom. We never had any training, we never went to university to be teachers, we don't know the first thing about it. We can speak our language but how do we go about teaching it?... That was my fear...it was so many years since I'd been in school... When I first started, it was really hard because I didn't have any materials. It all had to come out of my mouth and I was just exhausted because I was talking all day long (Note 1).

At provincial meetings over the last few years, discussions among Native language teachers have often focussed on the need for more systematic training.

There are obviously a number of options which could be explored in providing training for Native language teachers. The purposes of this paper are to describe our experience in Native language teacher training in two contexts in British Columbia, to describe some of the work done with students, to provide some examples of the materials and teaching plans students developed, and to make some suggestions, based on our experience, about Native language teacher training in Canada.

\section{UNIVERSITY-BASED TRAINING}

The first teacher-training context is a course offered to a group of Native people by Simon Fraser University as part of an off-campus, 
comprehensive teacher-training program. This program was offered in Prince Rupert, a city on the northwest coast, and students in the program came from a variety of northern communities. The course "Teaching a Native Language" was an experimental course given by the Faculty of Education in the fall of 1983. All students taking the course had had previous pedagogy courses and classroom-based practicum experience, and were thus familiar with the processes of lesson-planning, lessonperformance and the normal demands of university courses. The languages with which the twelve students in the course were concerned were quite varied: they wanted to teach Haida, Tsimshian (coastal and interior), Kwak'wala (two dialects) or Nishga. Conveniently, there were at least two students in the class concerned with each language, so students could work co-operatively on development of materials. Not all students in the class were themselves fluent speakers of these languages, but these non-fluent students were interested in learning their languages with greater proficiency and they believed that they might be able to assist the Native language teachers in their communities to plan high quality programs. All students had taken at least one Native language linguistics course as part of their university education.

Initially, students in "Teaching a Native Language" were asked to reflect upon their own experience as language learners, and to articulate on this basis what they felt was most important in leading to successful language learning. The following excerpt from one student's contribution shows how reflecting upon one's own experience in language learning can provide a very rich basis for building a language teaching theory:

I am bilingual. I can speak, read, write, and understand both English and Tsimshian languages. My proficiency in both languages is above average. I can speak both languages fluently. Reading comprehension and writing the English language used to be quite difficult for me because of a very limited vocabulary. Most of the time the reading materials provided were irrelevant. I was able to read about horses, fences, rabbits, but it meant nothing to me because none of these existed in my community. Even in high school I had to work extremely hard and consistently to achieve a passing grade. Again my main drawback was vocabulary. The transition from a very unique culture to a foreign way of life was very difficult... I was very much aware of my low competence in English so I remained silent most of the time, afraid to speak up lest I be ridiculed.

The turning point for me in learning the English language was when I suddenly realized the importance of learning the language... To learn a second language and become competent in it, I think one would have to have a purpose for it; the need for it. The desire to learn and a willingness to take risks must also be present. There 
must also be a good understanding of the cultural differences as well as constant encouragement from the parents or loved ones or even the community. The community must also be aware of the purpose and the importance of acquiring another language. (Beatrice Robinson, 1983, Note 3).

Some conditions which Robinson and the other students saw as important and facilitating in their own language learning were: realizing the importance of the language, learning language relevant to one's own experience and background knowledge, having real purposes for learning, and having community and familial support for language learning. These conditions then were applied as criteria throughout the course either for evaluation of the Native language lessons planned and performed, or for speculation about the possible future success of particular Native language programs.

After considering personal experiences, class discussion focussed upon the variability of language depending on setting, participants, and purposes. Using Hymes' (1972) discussion of the components of speech acts, Halliday's (1973) discussion of functions of language in first language acquisition, and Fishman's (1965) discussion of "domain," students considered how language is used to accomplish specific purposes and how these purposes could be accomplished using a variety of language forms. Students then considered English and Native language use in the communities in which they wished to teach, that is, where the Native language and English were used in their communities, by whom and for what purposes.

Lisa Clifton, a student concerned with the teaching of Smy'aalx (a dialect of Tsimshian) wrote the following about language use in Hartley Bay, a small community on the northwest coast:

The people in Hartley Bay from about 35 up speak their language quite fluently. It is an everyday language for them. And they feel comfortable speaking it no matter where they are. The people from 35 years and down to about 20 can understand, but aren't fluent speakers. These people speak Sym'aalx only when necessary-that is when a fluent speaker is asking them a question of great importance and does not want a non-speaker to undersatnd. From age 20 down they could probably understand short sentences like "Where are you going?", "How are you?" etc. and could probably pronounce names of Indian foods, towns, people and tribes. The elders speak strictly in Sym'aalx and find it very difficult to speak English. The children are rarely spoken to in Sym'aalx and rely heavily on a person who speaks both Sym'aalx and English for translation. The reason for this situation, I suppose, would be the school system and the fact that children like to play outside a lot. They are hardly ever around the elders anymore. There was a time when the elders taught the very young; now they 
are sent to modern schools to be taught by strangers... The language is used at home on a regular basis; it is used on the streets and over the phone. It is very much a part of their (people over 35) everyday lives. People who go to live in Hartley Bay and don't understand the language, must pick up quite fast in understanding if they want to be part of a conversation. The Sym'aalx speakers don't mind at all if a non-Tsimshian answers them in English. They are quite happy just to know that you can understand (Note 2).

Clifton's description above reports quite extensive use of the Native language by older speakers. In other northern communities described by the students, it became evident that Native languages are used in much more restricted contexts, although for all communities, students reported that Native languages are used at ceremonial occasions, mainly by elders and that the purposes for Native language use at ceremonies are social as well as religious. Students who described coastal communities also reported that Native languages are commonly used on the citizen band radios of fishermen when describing to each other fishing conditions in particular locations. Using the Native language is a way to prevent nonspeakers (importantly, non-Native fishermen) from benefitting from information transmitted on the radio. For many communities students stated that school children are now almost without exception, beginning learners of the Native language, and that currently, children would most likely use the Native language they learned with elders or persons over the age of about 40 .

Some students commented that the assignment had helped them think about Native language learning as not only a matter of learning a writing system; they remarked that during their linguistic training they had spent great effort learning the orthographic system for writing and reading their languages and that they had previously considered Native language teaching exclusively to be helping students become literate in that Native language. This exercise helped students see the possibility of teaching children oral language forms which they might use immediately outside the classroom with Native language-speaking adults.

Subsequently, students discussed "skills" in language learning and considered the relative importance of reading, listening, speaking and writing in language maintenance programs such as those in which they hoped to become engaged. Fishman's (1980) argument that literacy is essential for language maintenance programs was considered. Language maintenance efforts in other "Fourth World" communities were also discussed (see, for examples, Bartels and Bartels, 1984; Daniels, 1984). ${ }^{4}$ Some students argued that their community's Native language program should stress the four skills about equally; other students, whose languages had no or an extremely small written literature, saw a concentra- 
tion on oral/aural skills as more important. This principled consideration of the importance of teaching some or all of the four skills appeared to be a very valuable experience for students, and they commented upon the advisability of re-evaluating decisions made about the emphases programs should have if sociolinguistic conditions changed in their communities.

After this theoretical orientation, practical language teaching techniques were considered. Students initially indicated some skepticism about the possibility of teaching Native languages without extensive English interpretation. The instructor demonstrated, therefore, a number of techniques, teaching students forms in languages none of them knew. For example, it was demonstrated how classroom language (directives such as "Sit down, open your books, close the window" and others), could be easily and quickly taught in any second language. Students then alternated between being language learners and language teachers as they tried to apply what the instructor had demonstrated to teaching some item in their own language to their peers. Students also created materials such as puppets, language games, "language master" cards, stories, and picture charts and gained experience using various methods of lesson presentation. Students, in fact, did a lot of teaching of peers. The experience each student gained in presenting lessons to class members, many of whom did not know the language being taught, appeared to be more authentic and worthwhile than seems usually to be the case when language teachers "try out" their ideas on other teachers who share a common language.

Most of these Native language teachers will be working with school children who are beginners in their Native language; the Prince Rupert students' classmates were certainly beginners in some of the languages being taught, and the necessity for clear modelling, much repetition and attention to meaning quickly became evident. The students and the instructor learned how to greet an elder in coastal Tsimshian, how to talk about aches and pains in Haida, how to praise a child in interior Tsimshian. While having a very good time developing a classroom interlanguage, students also became aware of possible problems beginners might face. Another value of the presentation of a number of lessons for such a wide variety of languages was that students could readily see possible areas of co-operation between language groups despite the very great structural differences between the languages. Students could share general ideas about worthwhile language tasks as well as ideas about lesson presentation. Students could readily see that visual materials at least could be shared by groups whose linguistic backgrounds differed radically but whose cultural, physical and social environments showed some similarities. 
As already mentioned, there were a few students in the class who, although they did not claim fluency in the Native language of their community, were very interested in learning and teaching it. For the benefit of these students in particular, an attempt was made to discuss efficient and effective ways of eliciting language from expert informants and the mechanics of team-teaching with a fluent speaker who may not be a trained teacher. The time which had been spent on discussing the variability of speech according to setting, purposes, and the identity of participants, helped students design questions which would elicit the sorts of language forms the informants thought appropriate in various situations. An example might make this clear: in working with an informant, a student might ask "What would an older person say if she met her granddaughter at a feast? Would she greet the granddaughter? What would she say? What would be polite for the granddaughter to say back? What would the older person say if she met some child she was not related to? What should the child say back?" With clear expectations that language forms would vary depending (at least) on setting, participants and purposes, students could plan questions to elicit language from an informant in relatively efficient ways. The time-consuming task of working with an informant became somewhat easier as students could "pre-plan" their sessions to some extent. Students were enthusiastic about how much they learned in these planned conversations with informants, not only about their language, but also about their culture.

There were also opportunities for some students to practise teamteaching with other students within the course, as more fluent-speakers would work with less-fluent speakers in lesson presentation. These practice sessions made it very clear to students that working with another teacher takes an enormous amount of preparation but that team-teaching of language lessons can be personally and professionally enjoyable and also pedagogically sound. Students also gained confidence in their own language learning abilities as they worked with more-fluent speakers and learned some new language forms to the expert's and their own satisfaction.

A final assignment for students was to create a "unit plan" of two weeks of language lessons. James Young's unit plan for teaching body parts in Haida shows how this student implemented some of the ideas presented in class (see Appendix 1). Young's unit is focussed on the teaching of labels for body parts, but it does not stop at identification (so that children would be producing only nouns, which is where many units on this topic tend to end). In this unit children move from simple identificaiton in the first lesson (where children produce sentences which can be glossed as "Touch your $X$ " and sing a song where they produce only the nouns), to stating the function of various body parts, and then to understanding and 
producing directives concerning movement of body parts in a Haida dance. The university students were explicitly asked in preparing their lessons not to translate language forms into English, to ensure that when they considered structural sequencing of forms they were not confused by English structuring, and to encourage them to start preparing as much as possible of their Native language lessons in the Native language.

Young's unit shows a variety of kinds of activities. The unit is intended for students at a primary level and incorporates a final activity which would involve children and elders. Many students attempted to plan activities which would involve community members in language classes. For example, one student's unit, which was focussed on food animals, culminated in a mini-feast where children invited parents and elders and used the language forms they had learned in the unit to offer food to and discuss food with their guests.

The unit illustrated here and most of the other units developed by students are "functionally-driven." Most students were not especially skilled at grammatical analysis of their languages and they may need to consider structural sequencing more carefully when they are actually teaching their students. On the other hand, the functional orientation of the students' lessons, and the attention students paid to selecting language forms which would be of immediate use or interest to teach to their students, was extremely interesting, and we suspect, quite likely to be successful in classrooms. Certainly the motivation and the dedication these students showed in finding effective ways to teach their languages to school students will be instrumental in the results of the future programs.

\section{WORKSHOP-BASED TRAINING}

The workshop-based Native language teacher training we will describe was provided for teachers of a Salishan language, Halq'emeylem. Speakers of Halq'emeylem live on reserves in the Fraser Valley near the densely populated area of the Lower Mainland area of British Columbia. This training was not a "program" or a "course". Rather, it involved giving a series of workshops over the period of several months to practising teachers of the Native language.

The workshops we described here were given in 1983 and 1984. The Halq'emeylen teachers, like many other Native language teachers in the province, have had some previous training and there is available to them a "core curriculum." In 1974, a group of teacher-trainees worked intensively for ten weeks with a linguist who had developed an orthographic system for Halq'emeylem. In 1977 one of these teacher-trainees was hired by the district Indian Education Centre to develop Halq'meylem curricu- 
lum. With the help of the linguist, and using Teaching Algonkian as a Second Language (1974-76), a comprehensive series of lesson plans for teaching Hal'qemeylem was developed. Since then, many more materials have been developed with the help of a local artist; in addition, work is proceeding on the transcription of tape recordings of conversations and storytelling of elders.

Halq'meylem is currently taught to school students on an average of 3 times per week for about 20 minutes per class. The community is reported to be very supportive of the school Halq'emeylem language program and we observed a great deal of obvious enthusiasm on the part of the children for their Halq'emeylem classes.

While a great deal has been accomplished in this Native language program in a relatively short period of time, the teachers in the program have requested teaching methodology training as they feel that their work with students in classrooms could be improved. Because of this perception of the teachers, in February, 1983, a series of language teaching workshops was planned.

Before describing the series of workshops, it will be helpful to describe briefly what sorts of activities are occurring in the Halq'emeylem classes. Fluent speakers of Halq'emeylen are, in this area of the Fraser Valley, usually over 50 years of age. There are younger fluent speakers, but there are not many, and most, if not all, students entering school in this area are English speakers and are beginners in Halq'emeylem. At two of the schools where Halq'emeylem is taught, elderly fluent speakers team-teach with younger, less fluent speakers (in both cases, younger kin). At one school, teachers make consistent use of "Halq'emeylem readers." These readers have been prepared by a non-Halq'emeylem person who does not speak Halq'emeylem and who has attempted to translate simple English stories using using a dictionary. The Halq'emeylem teachers themselves have not yet created any readers, nor are they consulted directly in the creation of them. In classes, students choral-read stories from these readers and are asked to translate them into English. Use of these reading materials is the main focus of the language classes from grades three to six. With younger children in both schools, the teachers' lessons revolve around teaching students single words, usually nouns. Students also play some games ("Bingo" and "Concentration") where Halq'emeylem nouns are elicited, but all surrounding "game talk" is in English. All classroom directives are given in English. The kindergarten classes are normally given one new noun a day and then are asked to colour pictures of the noun. Children are also sung to, and they learn Halq'emeylem songs. One team of language teachers is responsible for teaching grades kindergarten to 12 in one school and they commented on the difficulty they experienced working with older students. No one is currently developing materials for 
the secondary level.

The teacher training workshops given to these teachers included a presentation by Pauline Alfred, whose remarks on Native language teaching are cited earlier in this paper. Beyond the obvious benefits of having a practising teacher share her ideas, materials and experiences, the demonstration of Kwak'wala lessons (a language none of the Halq'emeylem teachers knew), made evident the necessity for repetition, explanation of sounds and demonstration of meaning. In other workshop sessions, when teachers constructed lesson plans and demonstrated them to each other, it was apparent that the Halq'emeylem teachers were perhaps a little hasty and did not allow the time beginners would require for repetition, and they also sometimes assumed understanding of meaning without much demonstration. The language teaching workshop was, of course, composed of persons concerned with the same language. As the fluent speakers of Halq'emeylem in the class required no explanation or repetition and the non-fluent speakers were somewhat shy about indicating they needed more practice (or did not understand what was being said), the necessity for repetition and demonstration in teaching beginners was not as evident as it could have been.

Initially, it was anticipated that some workshop sessions would address the problems of syllabus development and that participants would gain experience co-operatively working on the development of several thematically-based "units" for language teaching. However, the teachers had had little previous general training in pedagogical techniques and were thus relatively unfamiliar, for example, with strategies for effective classroom management, grouping children, or providing a variety of activities. The decision was made to focus most directly with these teachers on pedagogical techniques.

Participants began to construct teaching games and materials. Examining the attractive "trail games" and visuals used by Alfred in the Alert Bay Kwak'wala program and those prepared by students in Prince Rupert, provided a strong impetus for creating similar Halq'emeylem materials. Participants were shown how to group students and had practice in this. Probably the most useful activity with the teachers involved the trainers observing Halq'emeylem classes and then holding consultations with the teachers immediately afterwards. In these sessions, all the other Halq'emeylem teachers were observers and they commented that watching another teacher work with children was very valuable for them and that the immediate reactions of the instructors and the other teachers to lessons permitted very constructive and helpful criticism. During one observation session, for example, when a teacher used a "Bingo" game she had constructed during a workshop session, participants suggested that she might use a child as a "caller" occasionally and that she might 
teach students "game language" in Halq'emeylem. The observers also worked out how one might say "I got it!" in Halq'emeylem, instead of "Bingo!". After another observation, participants composed a song to teach students labels for body parts. After observing the students who were working from the "Halq'emeylem readers," participants discussed how they might correct some of the grammatical and lexical errors in these books and how they might begin to create their own readers.

Providing Native language teacher training in an in-service situation, where trainees usually have not had previous training as teachers, and where training is not leading to some form of credit or certification, seems to us to be much more difficult than it is in a situation like the Prince Rupert case described previously. Native language teachers have many other pressing responsibilities in addition to in-service training workshops, and the time for training is often very limited. As very few extensive Native language curricula have been developed in Canada, curriculum development is a task often assigned to the Native language teachers themselves. Curriculum development for other sorts of subjects taught in schools is not usually a task assigned to untrained teachers or even to trained teachers who have little experience. In a workshop situation with Native language teachers, a trainer often sees a need to model and help students practise basic pedagogical technqiues, as well as a need to plan basic curriculum, and develop teaching materials and other resources. It may well be, as Kirkness (1984) suggests, an impossible task which faces Native language teachers, and trainers of Native language teachers will have to be careful that their task does not become equally impossible.

\section{CONCLUSION}

In the Prince Rupert case, a university-based course, students developed excellent curricular materials and had the time to consider some of the basic foundations of language teaching as well as to practise language teaching techniques. Such a situation is currently perhaps one of the most facilitating for training Native language teachers. However, we believe that workshop-based training also has possibilities for improving Native language teaching, if the very real limitations of these situations are recognized. The following are some suggestions about such training and other in-service Native language teacher training.

Our first suggestion concerns the sequencing of objectives for workshop-based Native language teacher training. We have concluded that it is unrealistic to expect untrained teachers who have ongoing responsibilities for classroom management and language teaching to carry on extensive, comprehensive and systematic curriculum develop- 
ment. While we personally believe that experienced classroom teachers (the "front line workers") are the most appropriate curriculum developers there are, we do not think that inexperienced and untrained teachers are comfortable or effective with this kind of work. They should become so, but this is not a realistic expectation to have at the beginning of their training. Therefore, workshop-based training with teachers who need ideas about such basic issues as effectively managing students in their classrooms should initially focus on teaching techniques and not on comprehensive syllabus development. If it is assumed that teachers will have an easier time managing students if they have some board games, songs, worksheets, other resources, and some knowledge about and experience in managing large groups of people, then training should focus on these aspects initially. A trainer can assess with the Native language teachers what needs to be done by observing in Native language classrooms. If workshop-based Native language teacher training initially focuses on the very real practical problems facing Native language teachers, and aids teachers with these problems, the teachers will be in a better position later to benefit from the theoretical understanding of language, language learning and pedagogy, which provide the foundations for the principled development of curriculum.

In the Halq'emeylem case, we were most successful in identifying problems teachers faced and in suggesting realistic solutions to those problems, when we were able to integrate workshop time with observation of classes with actual students. Integrating observation with workshop time is useful not only for identification of problems, but also for teachers to experiment with new teaching styles or materials. The workshop participants should be able to observe each other's experimentation, either by the group's actual presence, or by videotaping lessons for later discussion.

In British Columbia, and in other parts of the country many Native students are beginners in their language. Many Native language teachers then, are dealing with Native-as-a-second-language students. The Prince Rupert experience showed the benefits of having a variety of language backgrounds represented in teacher training sessions, so students became familiar with techniques which are necessary with beginners. Naturally, this mix of language backgrounds will not always be possible in teacher training sessions and in those cases, it would seem important that ways be found for teacher trainees to have supervised practice with beginning language learners and not just with fluent peers. Ideally, the beginners are available immediately in the workshop; if this is not possible, again, videotaping lessons for later discussion, or having a small group of children available for participants to "try out" their ideas on, may be feasible. In any case, we think it important that teachers get a chance to try 
out their ideas during the training sessions on learners who have some of the same characteristics as their students, especially if one of those characteristics is beginner-level proficiency.

Although we did not set this up either in Prince Rupert or in the Fraser Valley, it seems logical that observation of other language classes (French or heritage language) may also be of benefit to Native language teachers. In regular teacher training, a great deal of time is usually devoted to having the student teacher observe other teachers. That observation is assumed to help the student teacher assess particular techniques, "pick up" appropriate teacher behaviours and to help the student teacher become socialized to the culture of the school. Very rarely do Native language teachers have the time to observe in any classrooms at all, even in their own schools. Spending workshop time observing other teachers, especially other language teachers, and then discussing with the trainer what was observed, may be a very valuable activity.

Our final suggestion about Native language teacher training concerns relations between regular classroom teachers and the Native language program. We believe that it is essential that all school staff be aware of the importance of Native children learning Native languages and be aware also of some of the difficulties facing the teachers of Native languages. If regular classroom teachers can be as supportive as possible and can contribute to the on-going professional development of the Native language teachers, we believe programs can be affected in a very long-term sense. It may be that the Native language teacher trainees should spend a workshop session working with the regular classroom teachers discussing, for example, the difficulties of providing quality programming when teaching in closets or basements, or "on the run," when one has little support material to work with, or no-curriculum, or when one has responsibility for programming for students from kindergarten to grade 12. As qualified and trained teachers, regular classroom teachers should be resources for the Native language teachers, and they should understand that successful Native language learning will contribute significantly to the students' self-esteem and probably to their performance in other school subjects. If teacher training sessions can initiate a process of co-operation and mutual sharing among Native language teachers and other classroom teachers, that would be a very important outcome indeed.

\section{FOOTNOTES}

1 The authors would like to thank most sincerely those students who participated in Education 488: Teaching a Native Language (Faculty of Education, Simon Fraser University), in the fall of 1983; the Halq'emeylem teachers with whom we worked in 1983 and 1984 in the Fraser Valley; and Pauline Alfred of Alert Bay. All these students and the 
teachers were remarkably dedicated, conscientious and stimulating. This paper reports only a small part of the excellent work done by all participants. We realize our privilege in being able to work with these Native language teachers and teachers-to-be. An earlier report on the teacher training programs described in this paper was presented at the TESL Canada Conference in Winnipeg in June 1984. That report was published in the proceedings of that meeting in the TESL Manitoba Journal, volume 1, number 1.

${ }^{2}$ The term "Native" refers to persons who identify themselves as being of aboriginal North American ancestry.

${ }^{3}$ One of the B.C. universities, the University of Victoria, has set up a program for the training of Native language teachers. This program includes several courses in linguistics as well as language pedagogy, but it has never been offered to any group or individual in its entirety. (Dr. Richard King, personal communication, 1983).

4 The book, The Fourth World: An Indian Reality by George Manuel and Michael Posluns (1976) has popularized the term "fourth world" in Canadian usage. The term refers to aboriginal peoples all over the world and points to commonalities of experience of aboriginal peoples, in their relationship with land and with their colonizer societies.

\section{REFERENCE NOTES}

Note 1. Alfred, P. (1982). Workshop presentation to teachers of Halq'emeylem, Chehalis, B.C.

Note 2. Clifton, L. (1983). Course paper: Education 488. Simon Fraser University.

Note 3. Robinson, B. (1983). Course paper: Education 488. Simon Fraser University.

\section{REFERENCES}

Bartels, S., \& Bartels, A. (1984). Affirmative action education programs for Siberian Native peoples. Canadian Journal of Native Education, 11(2), 27-53.

Daniels, D. (1984). Affirmative action in education in Inner Mongolia, People's Republic of China. Canadian Journal of Native Education, 11(2), 14-26.

Fishman, J.A. (1965). Who speaks what language to whom and when? $\mathrm{La}$ Linguistique, 2, 67-88.

Fishman, J.A. (1980). Minority language maintenance and the ethnic mother tongue school. The Modern Language Journal, 64(2), 167-172.

Halliday, M.A.K. (1973). Explorations in the functions of language. London: Edward Arnold.

Hymes, D. (1972). On communication competence. In J.B. Pride and J. Holmes (Eds.), Sociolinguistics pp. 269-293. Harmondsworth, England: Penguin Books.

Kirkness, V. (1984). Native languages: Confusion and uncertainty. Language Development in Education, I(1), n.p.

Manuel, G., \& Posluns, M. (1974). The fourth world: An Indian reality. Don Mills: Colier-Macmillan.

Teaching an Algonkian language as a second language. (1974-76). Toronto: Indian and Northern Affairs. 


\section{THE AUTHORS}

Kelleen Toohey teaches courses in language education and multicultural issues in the Faculty of Education at Simon Fraser University. Pamela Hansen is a Master's student in the Faculty of Education at Simon Fraser University. 


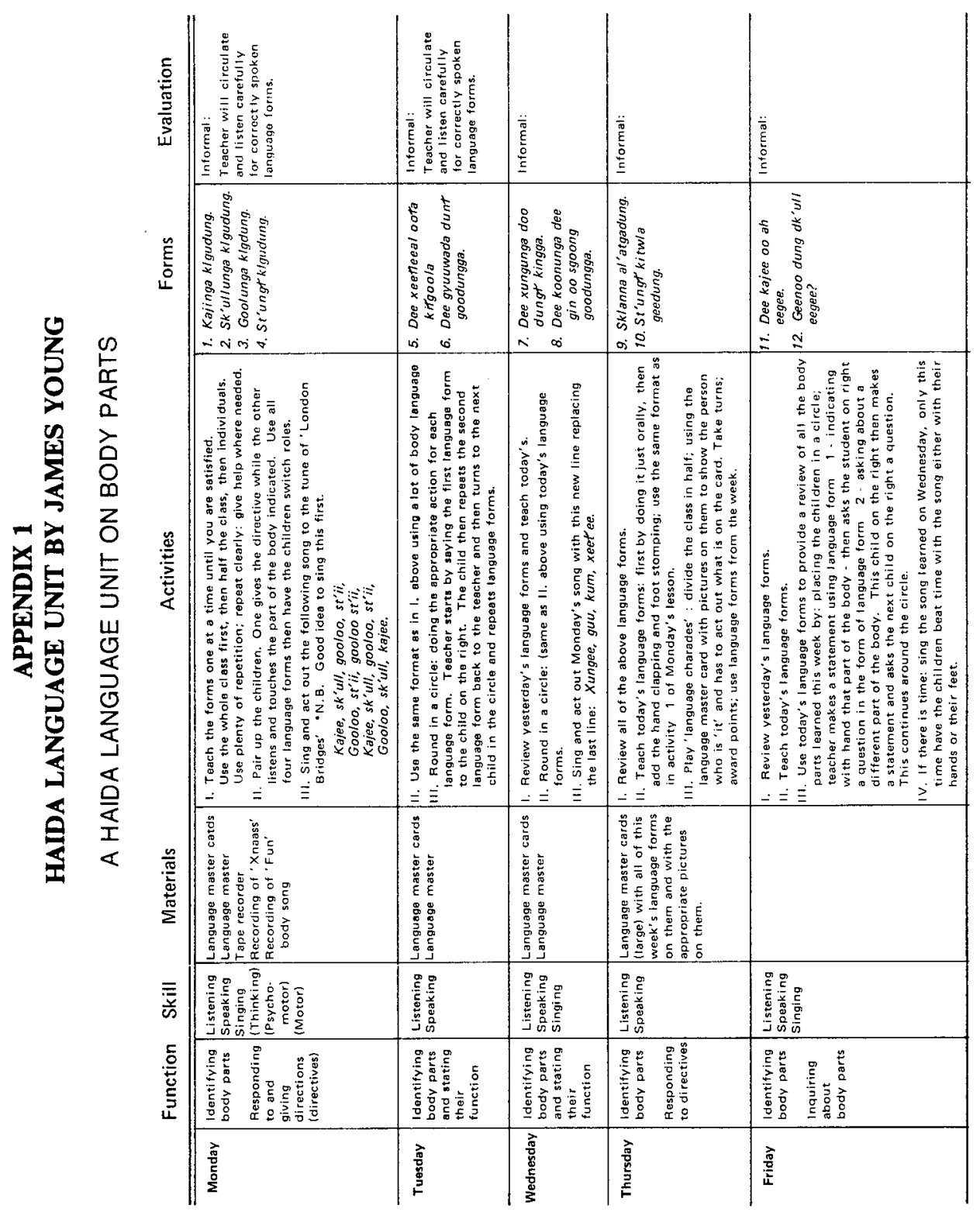




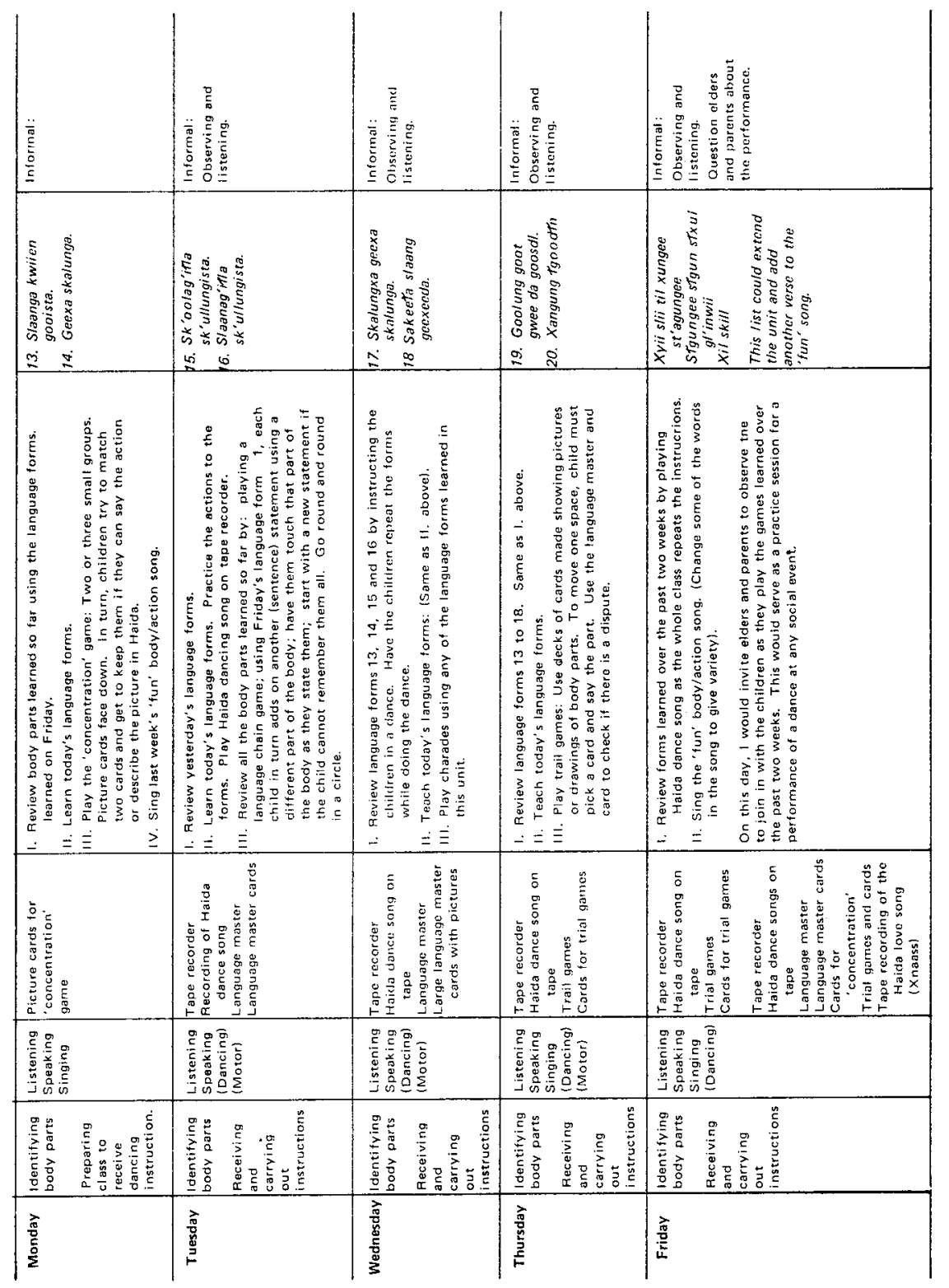

